\title{
LETRAMENTO LITERÁRIO: UMA PROPOSTA DE EXPERIÊNCIA ESTÉTICA NA FORMAÇÃO DOCENTE
}

\section{LITERARY LITERACY: AN ESTHETIC EXPERIENCE WITH TEACHERS OF THE PORTO VELHO MUNICIPAL NETWORK.}

\author{
Recebido: 30/12/2019 | Aprovado: 30/03/2020 | Publicado: 10/07/2020 \\ DOI: https://doi.org/10.18817/rlj.v4i1.2058
}

\author{
Larissa Gotti Pissinatti ${ }^{1}$ \\ Orcid ID: https://orcid.org/0000-0002-7964-7063 \\ Maria de Fátima Castro de Oliveira Molina ${ }^{2}$ \\ Orcid ID: https://orcid.org/0000-0001-8193-3088
}

\begin{abstract}
Resumo: Esse artigo tem por objetivo apresentar uma proposta de letramento literário feita com professores da rede municipal de ensino, do primeiro ciclo do ensino fundamental no município de Porto Velho - RO. O letramento literário é um objeto do conhecimento apresentado pela Base Nacional Comum Curricular e percebemos a dificuldade dos professores em executar uma metodologia que desenvolva o estético e o reflexivo nas crianças. Para desenvolver a proposta, utilizamos os seguintes fundamentos: Rildo Cosson, Hans Jauss, Wolfanglser, partindo do princípio de que a experiência estética é também uma experiência reflexiva e humanizadora e o professor deve ser o mediador no processo do contato leitor/obra. Utilizamos a metodologia da sequência básica, proposta por Rildo Cosson dividida em quatro momentos: motivação, apresentação, leitura e interpretação. A obra escolhida foi $O$ voo do Golfinho do autor Ondjaki. As atividades práticas realizadas pelos professores evidenciaram o interesse de todos em ampliar suas práticas pedagógicas, a fim de promover, pela escolarização da literatura, o letramento literário de seus alunos.
\end{abstract}

Palavras-chave: Letramento literário. Experiência estética. Formação do leitor.

Abstract: This article aims to present a literary literacy proposal made with teachers from the municipal school system, from the first cycle of elementar school in Porto Velho - RO. Literary literacy is an object of knowledge presented by the Common National Curriculum Base and we realize the difficulty of teachers in put into practice a methodology that develops aesthetic and reflective in children. To develop the proposal, we use the following foundations: Rildo Cosson, Hans Jauss, Wolfang Iser, assuming that the aesthetic experience is also a reflective and humanizing experience and the teacher should be the mediator in the reader/work contact process. We used the basic sequence methodology proposed by Rildo Cosson divided into four moments: motivation, presentation, Reading and interpretation. The work chosen was $O$ voo do Golfinho by author Ondjaki. The practical activities carried out by the participants evidenced the interest of all in broadening their pedagogical practices, in order to promote, through the schooling of literature, the literary literacy of their students.

\footnotetext{
${ }^{1}$ Graduada em filosofia pelo Centro Universitário Assunção - UNIFAI (2001). Mestre em Estudos Literários pela Universidade Federal de Rondônia - UNIR. Professora do quadro efetivo da Universidade Federal de Rondônia. Área de atuação em LIBRAS e Literatura Surda. Membro do grupo de pesquisa Letramento Literário: estudo de narrativas da/na Amazônia. E-mail: larissa.pissinatti@unir.br

${ }^{2}$ Graduada em Letras pela Universidade Federal de Rondônia (1992); Mestre em Ciências da Linguagem pela Universidade Federal de Rondônia (2008). Doutora em Letras pela UNESP Universidade Estadual Paulista Júlio de Mesquita Filho. Professora do quadro efetivo da Universidade Federal de Rondônia. Professora permanente do Programa de Mestrado em Estudos Literários/MEL/UNIR. Líder do Grupo de Pesquisa em Letramento Literário: estudo de narrativas da/na Amazônia. E-mail: fatimamolina@unir.br
} 
Keywords: Literary Literacy; Aesthetic experience; Reader Formation

\section{Introdução}

A formação do leitor literário é um desafio enfrentado pela escola tornando-se uma busca constante, bem como norteia as orientações curriculares propostas para o trabalho com a literatura nas diferentes modalidades de ensino. A experiência literária, processo resultante dessa formação, configura-se numa lacuna a ser preenchida nas práticas pedagógicas dos professores no trabalho com a literatura. Como se trata de um processo, a aquisição dessa experiência requer um planejamento específico de ações voltadas para propiciar o efetivo contato do leitor com o texto literário, ou seja, oportunizar o estranhamento, a participação do leitor numa contínua troca de significados.

A experiência relatada nesta abordagem foi motivada por essa problemática, vivenciada por professores que atuam no ensino fundamental, que revelaram suas dificuldades em desenvolver práticas de leitura literária com seus alunos, voltadas para a formação contínua do leitor literário. Ao encontro dessa solicitação, propusemos um curso de formação alicerçado nos pressupostos do letramento literário, sob a perspectiva teórica de Rildo Cosson, presente na obra Letramento literário: teoria e prática.

O relato que se apresenta delimita-se em abordar o processo de aplicação da sequência básica com os professores, a partir da leitura da obra $O$ voo do golfinho, de Ondjaki. A aplicação metodológica da seqüência básica, justifica-se pelas reflexões geradas mediante a execução sequencial das etapas de motivação, introdução, leitura e de interpretação. Cada etapa, em sua proposta diferenciada de ação, tem por objetivo propiciar um encontro significativo entre o leitor e a obra.

\section{O estético e o reflexivo no letramento literário}

O trabalho com a literatura sempre foi um desafio para a escola, principalmente com as crianças. Conforme Compagnon (2009), com o passar dos tempos, a literatura foi perdendo seu poder, em razão do trabalho, muitas vezes, reduzidos com os fragmentos propostos pelo livro didático ou de forma 
conteudística (trabalhando a gramática por meio do texto literário). A educação para o trato com o texto literário foi se tornando precária, como alerta Compagnon (2009) e também Cosson (2016; 2017), afirmam que, não raras vezes, em sala de aula, limita-se à leitura de pequenos fragmentos de uma obra ou com propostas de leitura por lazer. Reconhecemos o valor dessas iniciativas, porém não são adequadas quando se pretende desenvolver uma proposta de letramento literário no ambiente escolar.

Considerando esse contexto, já acenado por Antoine Compagnon no século XIX, observamos que a Base Nacional Comum Curricular - BNCC, apresentada em 2018, faz referência aos diversos tipos de letramentos, dentre eles, podemos incluir o literário. O documento compreende o literário como um "campo de atuação relativo à participação em situações de leitura, fruição e produção de textos literários e artísticos, representativos da diversidade cultural e linguística, que favoreçam experiências estéticas [...]" (BRASIL, 2018, p. 95). Além disso, observa nos objetos do conhecimento a formação do leitor literário como competência a ser desenvolvida no campo da linguagem.

No âmbito do Campo artístico-literário, trata-se de possibilitar o contato com as manifestações artísticas em geral, e, de forma particular e especial, com a arte literária e de oferecer as condições para que se possa reconhecer, valorizar e fruir essas manifestações. Está em jogo a continuidade da formação do leitor literário, com especial destaque para o desenvolvimento da fruição, de modo a evidenciar a condição estética desse tipo de leitura e de escrita. Para que a função utilitária da literatura - e da arte em geral - possa dar lugar à sua dimensão humanizadora, transformadora e mobilizadora, é preciso supor - e, portanto, garantir a formação de - um leitor-fruidor, ou seja, de um sujeito que seja capaz de se implicar na leitura dos textos, de "desvendar" suas múltiplas camadas de sentido, de responder às suas demandas e de firmar pactos de leitura. Para tanto, as habilidades, no que tange à formação literária, envolvem conhecimentos de gêneros narrativos e poéticos que podem ser desenvolvidos em função dessa apreciação e que dizem respeito, no caso da narrativa literária, a seus elementos (espaço, tempo, personagens); [...] (BRASIL, 2018, p. 136).

O conceito de estético apresentado no documento é compreendido como fruição. Ela é o elemento mobilizador dos processos humanizadores que a literatura pode oferecer. Avançamos aqui na reflexão, propondo na relação leitor/texto, a experiência estética/reflexiva, onde o professor é o mediador do processo e a fruição ocorre na medida que o leitor se identifica com o texto e esse toca seu contexto sociocultural. Portanto, a escolha da obra, por parte do 
professor e o processo metodológico no momento da leitura é de fundamental importância para que a formação do leitor literário e a experiência estética/reflexiva aconteça.

$\mathrm{Na}$ relação com a obra, o leitor estabelece uma relação com o texto. Compreenderemos essa relação a partir da estética da recepção de Hans Jauss, Wolfanglser e da experiência estética de Rildo Cosson pois, para esses autores a leitura do texto literário é concebida tanto numa perspectiva estética quanto reflexiva.

Os estudos da literatura, até meados do século XIX observavam os elementos sincrônicos, pautados na poética narrativa e em seus aspectos históricos. A partir do século XIX, novas perspectivas de análise e estudo da literatura surgem e dentre elas, a estética da recepção de Hans Jauss, propondo uma nova relação leitor/texto, cuja experiência estética pressupõe a recepção de uma determinada obra.

Para Jauss (2010), o estético e o reflexivo na experiência com uma obra literária têm como base a participação do leitor, pois ele ocupa o papel do receptor, interpretando, recebendo ou rejeitando elementos interpretados na leitura da obra e também produzindo, criando, refletindo e questionando aspectos que foram significativos durante o contato com a obra no decorrer da leitura. Esse processo de identificação com os aspectos significativos da obra e sua interpretação através da reflexão, elaborando novos pensamentos, questionamentos e relação com a própria vida é um acontecimento singular e individual no contato com a obra, interpelando o leitor, por meio de seu contexto de vida, a receber, de forma participativa e ativa a obra e seus elementos estéticos. Dessa forma, a experiência estética, caracterizada pelas impressões subjetivas do leitor e a emoção proporcionadas pelo texto, não é algo atemporal, mas se concretiza em um tempo e espaço oferecido tanto pela obra quanto pelo contexto sociocultural em que o leitor se encontra.

Conforme Jauss (2010), a obra é uma resposta às questões sincrônicas e diacrônicas do intérprete leitor e, o leitor, uma "nova inteligência da obra", pode, por sua vez, reconhecer no texto a sua reposta. Por isso ela proporciona uma experiência de recepção reflexiva, pois a leitura pode atingir questões cotidianas do leitor e contribuir no processo de projeção de novas ideias, transformando os 
significados construídos pelo leitor, oportunizando novas perspectivas e novos olhares em relação ao seu próprio cotidiano.

Nessa mesma perspectiva, Iser (1999), afirma ser a relação leitor/texto, um processo dialético, ou seja, há um diálogo entre leitor e texto onde um complementa o outro. O leitor não é um sujeito passivo diante da obra, mas participa, ao significar e interpretar o texto, pois o texto provoca um movimento de síntese no leitor, definindo novas perspectivas e significados. O texto, no que se refere ao seu sentido para o leitor, é recebido também em sua subjetividade, pois o leitor está situado em um determinado contexto históricocultural. Assim, na perspectiva de Iser (1999) e da estética da recepção, os sentidos não são determinados somente pelo texto, mas o leitor, em sua estrutura existencial (competência de interpretação, história de vida, contexto cultural), também irá determinar seu sentido e significado por meio da leitura. Isto porque, ao receber a obra, o leitor em um processo intersubjetivo, cria sentidos e significados. Esse processo é correspondente ao processo dialético promovido pelo texto no processo da leitura. Sobre essa concepção do sujeito como leitor ativo na relação com o texto, Iser (1999), afirma:

Para que o ponto de vista do leitor entre em cena, o texto precisa exercer
sua influência sobre a posição que aquele ocupa. Pois a constituição de
um sentido não representa uma exigência unilateral por parte do texto
ao leitor; ao contrário, o sentido só vem à tona se algo sucede o leitor.
Sendo "objetos culturais", os objetos não necessitam do sujeito por sua
própria causa senão para desenrolar-se nele [...] (ISER, 1999, p. 83).

Portanto, não é somente o que está posto no texto, em seu sentido verbal, que é compreendido pelo leitor, mas, na perspectiva estética, o sentido que o leitor concede ao texto também constitui parte de seu significado. Dessa forma, o que é representado no campo imagético do universo textual faz contato por meio do leitor e é combinado e dialetizado, gerando novas representações possíveis em sua interpretação no processo de leitura. Esse movimento dialético e a interrelação entre texto/leitor constitui o estético no letramento literário.

Iser (1999), assim como Jauss (2010), compreendem o processo de leitura como movimento de criação social. Dessa forma, o leitor, ao receber o texto e gerar novos sentidos, pode transformar e modificar sua prática social. Com isso, é possível considerar que a leitura de uma obra, em sua perspectiva 
estética, implica em proporcionar ao leitor uma oportunidade de criar novas perspectivas de si mesmo, do outro e do mundo.

Relacionado com essas noções está Cosson (2017), afirmando que por meio da leitura, o diálogo com outras experiências é possível. Assim, ler é produzir sentidos em uma atitude dialógica. Ainda conforme o autor, ler é uma "[...] competência individual e social, um processo de produção de sentidos que envolve quatro elementos: o leitor, o autor, o texto e o contexto" (COSSON, 2017, p. 36). Dessa forma, ler implica compreender os sentidos observando a obra e também o leitor em seu contexto social. Sem esse diálogo, a leitura é inconsistente. Lembrando que o leitor dialoga com o texto a partir das condições que lhe são oferecidas, tanto sociais quanto educacionais.

Segundo Cosson (2017), a identificação do contexto da obra literáriaindicada pelo autor é um importante fator de leitura.Quando isso não é feito, o texto passa de um objeto literário para um objeto didático de ensino de algum conteúdo, mas a experiência estética é deixada de lado.

Para facilitar esse circuito de leitura e experiência estética, Cosson (2016) apresenta uma metodologia para o letramento literário: a sequência básica e avançada. Apresentaremos nesse trabalho, apenas a sequência básica, objeto de nossa formação com os professores da rede municipal do primeiro ciclo do ensino fundamental.

Cosson (2016) divide a sequência básica em quatro momentos: motivação, introdução, leitura e interpretação.

O primeiro momento é considerado de grande relevância, pois irá aproximar o leitor da obra literária. Essa aproximação pode ser feita a partir de um tema que desperte a leitura e que tenha relação com a obra. Assim, pode ser proposta uma atividade individual ou coletiva de discussão, dinâmica, jogo, a fim de instigar o leitor a pensar na obra e relacionar com o tema proposto. Segundo Cosson (2016, p. 56), "a motivação exerce uma influência sobre as expectativas do leitor, mas não tem o poder de determinar sua leitura". Isso porque o leitor tem suas condições e contexto e, na leitura esses aspectos devem ser considerados.

No segundo momento, denominado introdução, pode ser feita a apresentação da obra e a exploração de seus elementos pré-textuais e póstextuais. Dentre eles, a capa e a contracapa também podem contextualizar a 
obra. Independentemente da estratégia utilizada, é importante que a obra seja apresentada fisicamente ao aluno, não perdendo de vista que o objetivo desse momento é que o leitor receba a obra de forma positiva e consciente da justificativa da escolha por parte do professor.

O momento da leitura deve ser mediado e cuidado pelo professor. Isso não significa "vigiar" o aluno durante a leitura, mas estar presente, tirar as dúvidas, acompanhar, se necessário ler para os que apresentarem mais dificuldades. Além disso, pode ser feita uma leitura conjunta e, posteriormente, uma discussão do que foi lido.

A interpretação é o quarto e último momento. É o momento de manifestação dos significados e sentidos que foram construídos ao longo de todas as etapas. Para Cosson (2016, p. 65), "a interpretação é feita com o que somos no momento da leitura. Por isso, por mais pessoal e íntimo que esse momento possa parecer a cada leitor, ele continua sendo um ato social". Isso significa dizer que ao manifestar suas impressões na interpretação seja por meio de texto, teatro, desenho, poesia, ou outra estratégia, se proporciona ao leitor um espaço onde ele pode projetar-se, criar, questionar, refletir e propor novas formas de perceber a realidade e até transformá-la. A materialização dos sentidos através da interpretação possibilita ao leitor deixar-se tocar por si mesmo e pelo mundo e dialogar com a realidade de si mesmo e do outro. Nesse momento a experiência estética com a obra e a experiência reflexiva se estabelecem de forma mais completa, possibilitando ao leitor dialogar com o autor, trazendo a sua perspectiva de leitura.

\section{A proposta metodológica da sequência básica}

O projeto de extensão "Práticas de letramento literário no ensino fundamental: uma proposta de formação docente" foi desenvolvido com professores de uma escola do município de Porto Velho-RO, com o objetivo de oportunizar uma reflexão teórica sobre o processo de letramento literário, a fim de instrumentalizá-los em suas práticas pedagógicas em sala de aula. A partir do estudo teórico, foram trabalhadas metodologias para promover o letramento literário dos seus alunos, por meio da proposta metodológica da sequência básica 
para o trabalho com a literatura infantil em sala de aula. As ações foram realizadas dentro de uma carga horária de 16 horas, no espaço da biblioteca da escola.

Os procedimentos metodológicos adotados durante a execução do curso foram desenvolvidos por meio do estudo reflexivo da teoria e da aplicação da sequência básica proposta por Cosson (2016), na obra Letramento literário: teoria e prática. À luz dessa proposta metodológica, foram desenvolvidos os quatro passos da sequência básica: motivação, introdução, leitura e interpretação.

Essa etapa da identificação dos conceitos e de reflexão da metodologia foi seguida da aplicação prática com a leitura da obra $O$ voo do golfinho, do autor angolano Ondjaki, com ilustrações de Danuta Wojciechowska, publicado em 2012 pela Companhia das Letrinhas. A densidade simbólica da obra já se revela na capa por meio do título e da ilustração de um golfinho estampado com vários pássaros coloridos. A narrativa conta a trajetória de um golfinho diferente, com uma identidade híbrida, era golfinho, mas também se sentia um pássaro, com habilidades de pássaro. Um dia, ao saltar, outro golfinho lhe disse que parecia um pássaro. Certa vez, fez um salto muito alto e pode se observar no espelho d'água produzido pelo mar. Percebeu, então, que tinha um corpo diferente, além do bico, tinha corpo de pássaro e foi assim que partiu do mar e passou a brincar nas nuvens com outros pássaros. Quando observou seus colegas, percebeu que eles também tinham sido outros animais e agora eram pássaros, assim como ele. Agora eles podiam voar juntos e livres, do jeito que haviam sonhado. Assim como mostra a capa da obra, abaixo. 
Fig. 1

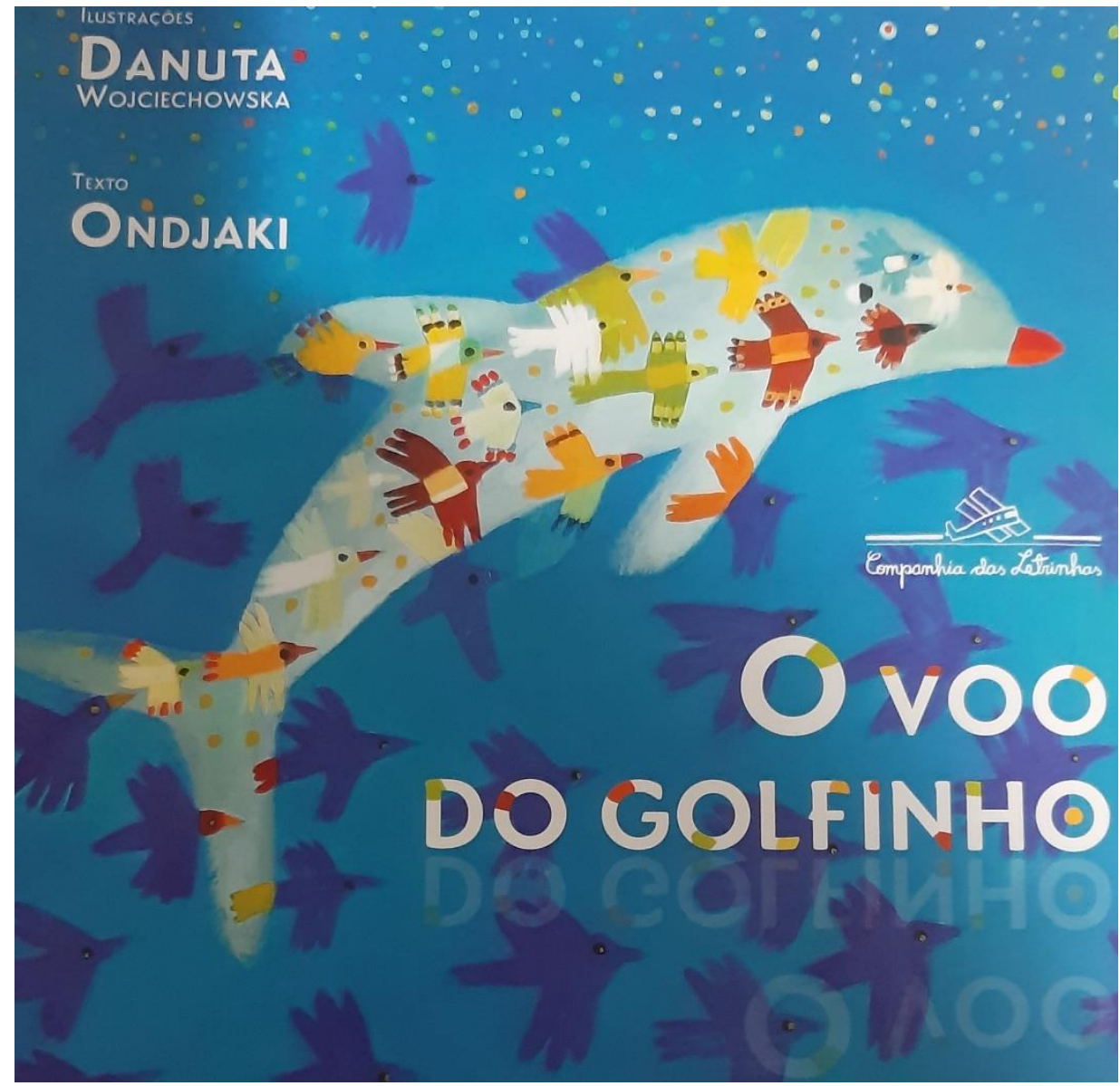

Fonte: capa da obra (ONDJAKI, 2012)

O encaminhamento metodológico inicial foi explorar o elemento lúdico a fim de fazermos a inserção da obra no contexto dos professores. Dessa forma, para o primeiro passo da motivação, ou seja, a preparação inicial para propiciar o encontro do leitor da obra, suscitamos questionamentos sobre identidade, se são felizes como se representam, o que mudariam ou como gostariam de ser. $\mathrm{O}$ objetivo com tais questionamentos era adentrar na temática da obra, antecipando a discussão sobre comportamentos, fases da vida, transformações e a relação entre identidade e felicidade. Essas estratégias iniciais vão ao encontro das proposições de Cosson, assim definidas:

Ao denominar motivação a esse primeiro passo da sequência básica do letramento literário, indicamos que seu núcleo consiste exatamente em preparar o aluno para entrar no texto. O sucesso inicial do encontro do leitor com a obra depende de boa motivação. [...] as mais bem-sucedidas práticas de motivação são aquelas que estabelecem laços estreitos com o texto que se vai ler a seguir. A construção de uma situação em que os 
alunos devem responder a uma questão ou posicionar-se diante de um tema é uma das maneiras usuais de construção da motivação (2016, p. 54).

Dessa forma, para essa antecipação prevista pela motivação, exploramos elementos relacionados à temática da obra antes mesmo do efetivo contato entre a obra e os professores. As discussões sobre o tema apresentado, os diferentes posicionamentos $\mathrm{e}$ as reflexões suscitadas forneceram a base para prosseguirmos em direção à introdução.

$\mathrm{Na}$ etapa da introdução, direcionamos um momento para uma breve apresentação do autor da obra. Também exploramos a capa e os possíveis significados sugeridos pelo enunciado imagético e o enunciado verbal do título. $O$ estranhamento causado pela ação de voar atribuída a um animal aquático serviu de liame para relacionar a obra e a temática encenada. Assim, os efeitos de sentido gerados pela elaboração do título correspondem ao que Umberto Eco (1985) denomina de "chave interpretativa. Ao estabelecer as relações entre título e sentido, o autor postula: "Um título deve confundir as ideias, nunca disciplinálas" (ECO, 1985, p. 9). Nessa perspectiva, as apreciações críticas contribuíram para despertar a curiosidade dos professores sobre como esses elementos estariam relacionados coma narrativa. Logo, a estratégia da introdução de breve análise dos paratextos serviu para uma posterior recepção positiva da obra.

$\mathrm{Na}$ sequência, partimos para a leitura oralizada da obra, realizada por uma professora e acompanhada pelos demais participantes. Após a leitura, as ações foram direcionadas para a etapa da interpretação, o momento de construção dos sentidos mobilizados pela leitura. Segundo Cosson (2016), tratase de um momento que se processa em duas etapas, uma mais interior, de decifração, e a outra, mais externa, de materialização da interpretação.

No primeiro momento, do efetivo contato entre o leitor e a obra, todos os elementos de composição da narrativa ganharam visibilidade, de acordo com a experiência de leitura de cada um. No entanto, é interessante ressaltar que essa experiência também se constitui no social. Conforme elucida Cosson: "A interpretação é feita com o que somos no momento da leitura, por isso, por mais pessoal e íntimo que esse momento interno possa parecer a cada leitor, ele continua sendo um ato social" (2016, p. 65). Assim, naturalmente, esse momento 
de leitura convocou as práticas, os saberes e as vivências desses professores no espaço da sala de aula, sobretudo em suas práticas pedagógicas voltadas para a leitura literária. Envolvidos nesse processo, os professores foram percebendo as possibilidades de também aplicar essas estratégias metodológicas com seus alunos, na busca de tornar a leitura literária mais significativa. Houve a percepção de que nenhuma prática mais imediatista pode substituir o efetivo contato entre 0 leitor e a obra.

No segundo momento, de materialização dos sentidos, todos se demonstraram entusiasmados para a produção do registro e posterior compartilhamento. Antes, promovemos uma roda de conversa para debates sobre a temática que o livro apresentava. Os debates foram perpassados tanto pela a análise da narrativa, por meio das escolhas das personagens, a importância simbólica das cores e seus significados para a condução do enredo, quanto pela relação da temática com a realidade do universo do qual cada um fazia parte.

\section{A materialização dos sentidos}

O estudo teórico sobre as concepções que envolvem o processo de letramento literário pela aplicação da sequência básica foi ao encontro das buscas dos professores que ansiavam encontrar possíveis caminhos para um trabalho mais significativo, de envolvimento com a leitura literária em sala de aula. $O$ objetivo era encontrar meios para a realização de um trabalho que desse um tratamento diferenciado à obra literária. O pressuposto de que o trabalho com a literatura se realiza de forma processual revela a dificuldade encontrada pelos professores em desenvolver práticas que se tornem um fazer contínuo, conforme prevê a perspectiva conceitual alicerçada na proposta de Cosson: "O letramento literário possui uma configuração especial, voltado ao processo de escolarização da literatura, no sentido de reformar, fortalecer e ampliar a educação literária que se oferece no ensino básico (2016, p. 12). Logo, um trabalho voltado para a formação do leitor literário pressupõe um planejamento específico de ações que propiciem o efetivo contato do leitor com o texto literário.

O resultado desse efetivo contato revelou-se, sobretudo, na etapa da materialização dos sentidos construídos pela leitura da obra $O$ voo do golfinho. 
Nesse momento, os professores revelaram imagens de si e nas impressões de leitura registraram a necessidade de transformação para superar os obstáculos enfrentados no cotidiano de sala de aula.

Dessa forma, os professores vivenciaram, por meio de uma estratégia metodológica na perspectiva do letramento literário, caminhos que tornam possível o efetivo contato entre o leitor e a obra literária. De acordo com Cosson (2016), quando um leitor se apodera da Literatura como prática interpretativa do mundo, consegue transformar informações em conhecimento e transformar nas relações cotidianas. Consequentemente, o poder da palavra e da escrita acompanha essa experiência e promove o crescimento intelectual e social, formando sujeitos mais críticos e preparados para as possíveis práticas leitoras.

Em consonância com as concepções de Antonio Candido, a literatura com todas as suas possibilidades de leitura é um direito do homem, posto que "a literatura confirma e nega, propõe e denuncia, apoia e combate, fornecendo a possibilidade de vivermos dialeticamente os problemas" (CANDIDO, 2004, p. 175). Com esse conceito abrangente e necessário, a apropriação da Literatura é uma forma de enfrentar todas as peculiaridades que nossas relações sociais, históricas, políticas e culturais constroem em nosso dia a dia. Assim, experienciar o contato com a sensibilidade, o questionamento, a reflexão, a ampliação de horizontes, enfim, apreender as representações simbólicas das experiências humanas, por meio da literatura contribuem, sobretudo, para aprimorar a humanização do homem.

Nesse sentido, Regina Zilberman salienta a importância da leitura da literatura ao afirmar ser uma prática que reproduz a convivência com o mundo, posto que também é uma modalidade de lê-lo. Nesse sentido, a autora pontua que essa atividade de decifração não pode prescindir o texto literário, pois "a obra de ficção, fundada na noção de representação da realidade, exerce seu papel sintético de forma mais acabada, fazendo com que leitura e literatura constituam uma unidade que mimetiza os contatos materiais do ser humano com seu contorno físico, social e histórico" (ZILBERMAN, 2009, p. 32). Portanto, como exercício de interpretação dos significados ocultos que o texto literário suscita, a leitura da literatura configura-se em um modelo por excelência de leitura. Em sua 
realização, convoca a intervenção de um leitor para preencher lacunas e dar vida ao mundo formulado pelo escritor.

Dessa forma, há que se considerar a necessidade de se construir, juntamente com os professores, agentes das práticas de leitura em sala de aula, reflexões sobre como a leitura da literatura pode se apresentar como alternativa possível para transformar o aluno habilitado à leitura em leitor, por meio do letramento literário.

\section{Considerações Finais}

O trabalho com a literatura sempre foi um desafio enfrentado por professores preocupados com a formação de leitores competentes e bons apreciadores da literatura. A predominância de práticas metodológicas voltadas para o repasse de conteúdos deslocou o lugar ocupado pelo texto literário como veículo de fruição e experiência estética. O efetivo contato com a obra literária cedeu lugar à leitura de fragmentos para a identificação de elementos informativos do texto.

Contrapondo-se às práticas estéreis que desconsideram a especificidade estética no trabalho com a literatura em sala de aula, o letramento literário tem como proposta apresentar práticas significativas de produção de sentidos por meio do efetivo contato entre o leitor e a obra literária. Sob essa perspectiva, o objetivo é ampliar e enriquecer as práticas pedagógicas voltadas para a leitura literária no ensino básico.

Motivar o leitor a adentrar no universo temático da obra, introduzir parte desse universo por meio dos significados gerados pelos paratextos, propiciar o momento de leitura em seus dois níveis, de decifração interior e de materialização externa da interpretação e, por fim, instaurar a materialização dos sentidos por meio de registros é um percurso necessário para dotar o aluno da capacidade de se apropriar da literatura. Essas etapas configuram-se em caminhos viáveis para propiciar a inserção desse aluno no universo da literatura por meio do letramento literário.

\section{Referências}


BRASIL. SECRETARIA DE EDUCAÇÃO FUNDAMENTAL. Base Nacional Comum Curricular. Educação é a base. Ensino Fundamental. Ministério da Educação: Brasília, 2018.

CANDIDO, Antonio. Vários escritos. Rio de janeiro: Ouro sobre Azul/São Paulo: Duas Cidades, 2004.

COMPAGNON, Antoine. Literatura para quê? Trad. Laura Brandini. Belo Horizonte: Editora UFMG, 2009.

COSSON, Rildo. Círculos de leitura e letramento literário. São Paulo: Contexto, 2017.

COSSON, Rildo. Letramento literário teoria e prática. São Paulo: Contexto, 2016.

ECO, Humberto. Pós-escrito a O nome da rosa. Trad. Letizia Zini Antunes e Álvaro Lorencini. Rio de Janeiro: Nova Fronteira, 1985.

ISER, Wolfang. O Ato da leitura uma teoria do efeito estético. Vol 2. Traduçãode Johannes Kretschemer. São Paulo: Editora 34, 1999.

JAUSS, Hans R. Pour une esthétique de laréception. Gallimard: Paris, 2010.

ONDJAKI. O voo do Golfinho. Companhia das letrinhas: São Paulo, 2012.

ZILBERMAN, Regina. A escola e a leitura da literatura. In: ZILBERMAN, Regina RÖSING, Tania M. K. (Org.). Escola e leitura: velha crise, novas alternativas. São Paulo: Global, 2009. 